\title{
Effects of Methamphetamine on Regional Cerebral Glucose Utilization in Rats with Unilateral Lesion of Substantia Nigra
}

\author{
Yutaka GOMITA, Yasuyuki ICHIMARU1, Katsushi FURUNO \\ and Yasunori ARAKI \\ Department of Hospital Pharmacy, Okayama University Medical School, \\ Okayama 700. Japan \\ ${ }^{1}$ Department of Pharmacology, Daiichi College of Pharmaceutical Sciences, Fukuoka 815. Japan
}

Accepted April 18, 1990

\begin{abstract}
In rats with electrocoagulation of the unilateral subtantia nigra ( $S N$ ), methamphetamine at doses of 2.5 and $5 \mathrm{mg} / \mathrm{kg}$, i.p., induced ipsilateral turning towards the lesioned side and caused an imbalance of the regional cerebral glucose utilization (CGU) in the caudate-putamen (CP), frontal cortex (FC) and ventromedial thalamic nucleus (VMT); i.e., showing a higher contralateral CGU as compared with the SN lesioned side. These results induced in unilateral SNlesioned rats may be accompanied by an imbalance of neural activity in $\mathrm{CP}$. FC and VMT of these rats.
\end{abstract}

It is known that the substantia nigra (SN) and caudate-putamen (CP) are sites regulating the extrapyramidal systems $(1,2)$. Turning behavior has been mainly considered as the consequence of imbalance between the two nigrostriatal dopamine systems (1). Amphetamines such as amphetamine and methamphetamine (MA), which release dopamine from nerve terminals, induce ipsilateral turning behavior in rats with unilateral lesions of either the SN, CP or the nigrostriatal bundle (2). This turning behavior is thought to be a sequel of the release of dopamine from nigrostriatal dopamine nerve terminals contralateral to the lesioned side $(3,4)$. The ipsilateral turning behavior is also induced by dopaminergic drugs such as apomorphine in rats with unilateral lesion of the ventromedial thalamic nucleus (VMT) (5). The VMT is connected with the SN pars reticulata, forming a CP-SN-thalamus circuit and is concerned with registration of striatal dopamine-mediated behavior in drug-stimulated rats (6). The turning behavior induced by dopaminergic drugs like MA may be associated with not only nigrostriatal activity but also activity in the SN-VMT circuit. The purpose of the present study is to investigate the action of MA on neural activity of brain structures related to turning behavior, using [ $\left.{ }^{14} \mathrm{C}\right]$ 2-deoxyglucose (2-DG) autoradiography (7).

Male Wistar rats weighing 200-250 g at the time of surgery were used as subjects. They were housed two or three per conventional plastic cage, and given food and water ad libitum throughout the experiment. The animals were maintained on a 12 lightdark cycle (lights on 08:00 to 20:00) and at a room temperature of $22-24^{\circ} \mathrm{C}$ with a relative humidity of approximately $60 \%$.

Animals were anesthetized with sodium pentobarbiturate $(45 \mathrm{mg} / \mathrm{kg}$, i.p.) and then placed in a stereotaxic apparatus (Takahashi). Electrocoagulation was made in the unilateral SN based on the following coordinates: $A$. 2.2: $L, 2.0$; and $V,-1.7 \mathrm{~mm}$, according to the atlas of De Groot (8). A bipolar electrode (250 $\mu \mathrm{m}$ in diameter, insulated except at the tip) was used for electrocoagulation. The electrocoagulations were performed by passing electric current ( $1 \mathrm{~mA}, 10 \mathrm{sec}$ ) into the SN. All animals were subcutaneously given 100.000 units of penicillin after the surgery.

At the 7th day after the SN lesion surgery, the rat was given an intraperitoneal injection of $5.0 \mathrm{mg} / \mathrm{kg}$ MA. Twenty-five minutes later, the turning behavior was measured for 
$10 \mathrm{~min}$ in an open-field apparatus $60 \mathrm{~cm}$ in diameter). Those animals that showed ipsilateral turning toward the $\mathrm{SN}$-lesioned side for over 10 times in number and those below 3 times in number to the contralateral turning were used in the $\left[{ }^{14} \mathrm{C}\right] 2-\mathrm{DG}$ experiment. The turning behavior was observed even during $\left[{ }^{14} \mathrm{C}\right] 2-\mathrm{DG}$ incorporation.

The animals used for the MA $\left[{ }^{14} C\right] 2-D G$ experiment (7) were given the 2-DG within 2 weeks after the SN lesion surgrery. The rat that was placed in the box $(30 \mathrm{~cm}$ in width, $25 \mathrm{~cm}$ depth and $27 \mathrm{~cm}$ in height) was intraperitoneally injected with MA at a dose of 2.5 or $5 \mathrm{mg} / \mathrm{kg}$ and $\left[{ }^{14} \mathrm{C}\right] 2-\mathrm{DG}$ (Amersham) at a dose of $1.11 \times 10^{6} \mathrm{~Bq} /$ rat. The turning behavior was measured for 10 min each at 10, 20 and 30 min after administration of either MA or saline. At the end of the 45-min uptake period of isotope, the rats were anesthetized by the intraperitoneal injection of sodium pentobarbiturate at $45 \mathrm{mg} /$ $\mathrm{kg}$ and perfused intracardially for $30 \mathrm{sec}$ with $3.3 \%$ formalin buffered to $\mathrm{pH}$ of 7.4 (9). The brain was then removed, rapidly frozen in liquid freon at $-55^{\circ} \mathrm{C}$ and sectioned at 20 $\mu \mathrm{m}$ thickness in a cryostat (Bright) at $-18^{\circ} \mathrm{C}$. Each section was picked up by means of chilled coverslips $(24 \times 24 \mathrm{~mm})$ and dried on a warming tray at $40^{\circ} \mathrm{C}$. The coverslips were mounted on cardboards and exposed, along with autoradiographic $\left[{ }^{14} \mathrm{C}\right]$ micro-scales (1.15-32.7 KB/g, $120 \mu \mathrm{m}$ strip) for preparing the standard curve, using Kodak SB-5 $X$-ray film; the film was exposed for 10 days. Subsequently, the sections were stained with thionine and then used to identify brain portions on the autoradiogram. The autoradiographic images were analyzed by Computerized Image Processings (Magiscan-2 and Amersham RAS-1000). The index we used for the evaluation was $\mathrm{dpm}$ (disintegration $/ \mathrm{min}$ ) $/ \mathrm{mg}$ tissue obtained from the relative optical density (ROD). The ROD of one pixel to another is variable in darkness rank in the image. The regional cerebral glucose utilization (CGU) was estimated according to the standard curve ( 8 points, 89-2373 dpm/mg tissue).

Control rats (Rat $W-1$ and $W-2$ ) with a unilateral SN lesion, treated with saline, did not show an imbalance in turning behavior ( 2 to 5 ipsilateral turns: 1 to 3 contralateral turns in Rat W-1 and 0 ipsilateral turn: 0 to 1 contralateral turns in Rat $W-2)$. However, $\mathrm{MA}$ at doses of 2.5 and $5.0 \mathrm{mg} / \mathrm{kg}$, i.p., caused ipsilateral turning towards the $\mathrm{SN}$-lesioned side. The number of ipsilateral turns measured for $10 \mathrm{~min}$ each at 10,20 and $30 \mathrm{~min}$ after the administration was 15,13 and 20 , respectively, in Rat $W-3$ that was treated with MA at a dose of $2.5 \mathrm{mg} / \mathrm{kg}$; was 0.1 and 30 .

Table 1. Brain side-side differences in $\mathrm{dpm}$ (disintegration/min) $/ \mathrm{mg}$ tissue obtained from the [ $\left.{ }^{14} \mathrm{C}\right] 2$ deoxyglucose autoradiogram of rats with unilateral lesion of the substantia nigra

\begin{tabular}{|c|c|c|c|c|c|c|}
\hline & \multicolumn{5}{|c|}{ Non-lesioned side-Lesioned side } & \multirow{4}{*}{$\begin{array}{c}\text { Degree of difference } \\
\text { between drugged } \\
\text { and non-drugged } \\
\text { groups }\end{array}$} \\
\hline & \multirow{2}{*}{\multicolumn{2}{|c|}{$\frac{\text { Control }}{\text { Saline }}$}} & \multicolumn{3}{|c|}{ Methamphetamine } & \\
\hline & & & $2.5 \mathrm{mg} / \mathrm{kg}$ & 5.0 & $/ \mathrm{kg}$ & \\
\hline & $W-1$ & $W-2$ & W-3 & $\mathrm{B}-8$ & $B-11$ & \\
\hline $\begin{array}{l}\text { Frontal cortex } \\
(F C)\end{array}$ & 8 & -3 & 24 & 28 & 18 & marked \\
\hline $\begin{array}{l}\text { Caudate putamen } \\
\text { (CP) }\end{array}$ & 7 & 8 & 50 & 33 & 62 & marked \\
\hline $\begin{array}{l}\text { Globus pallidus } \\
\text { (GP) }\end{array}$ & -3 & 6 & 7 & -5 & 12 & no \\
\hline $\begin{array}{l}\text { Lateral thalamic } \\
\text { nucleus (LT) }\end{array}$ & 8 & -5 & 70 & -3 & 4 & uncertain \\
\hline $\begin{array}{l}\text { Ventromedial } \\
\text { thalamic nucleus } \\
\text { (VMT) }\end{array}$ & 12 & 9 & 107 & 20 & 64 & marked \\
\hline Ipsilateral turn & no & no & marked & narked & marked & \\
\hline
\end{tabular}


A

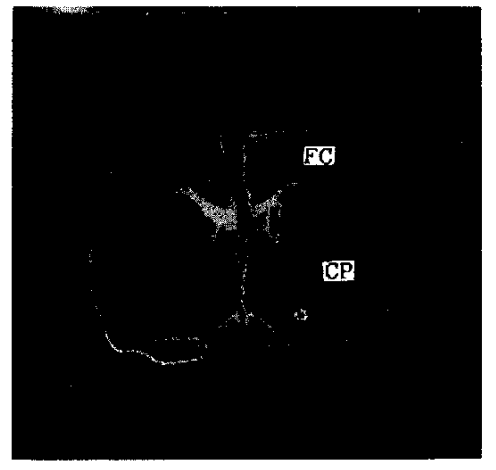

B

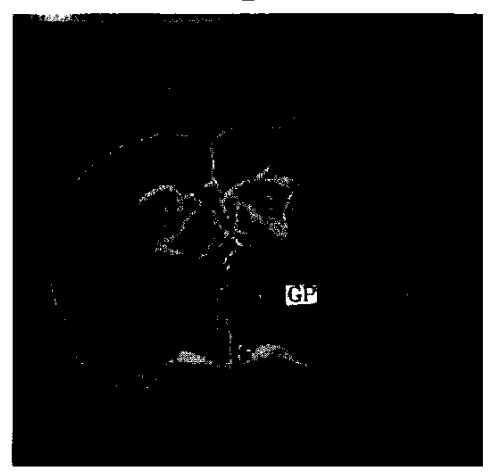

C

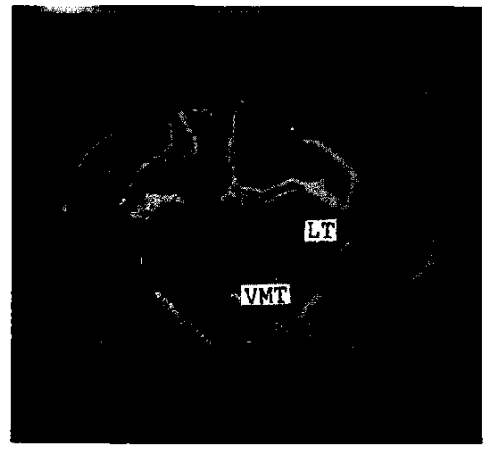

Fig. 1. Color displays obtained from the autoradiogram of coronal sections (Rat $\mathrm{W}-3$ ). The bands on top of each color display $(A-C)$ indicate the calibration for the degree of density of the autoradiogram. Red and yellow bands at the left side represent low density of autoradiogram. The blue color band represents high density, and thus, high concentration of $\left[{ }^{14} \mathrm{C}\right]$ in brain tissue. Section $A: A, 8.6 \mathrm{~mm}$ : section $B$ : A, $6.2 \mathrm{~mm}$; and section $C$ : $A, 4.6 \mathrm{~mm}$, according to the De Groot brain atlas (8). The lesioned area of the animals was located at the left $S N$. Reliable differences between both sides induced by respectively, in Rat B-8 that was treated with a dose of $5 \mathrm{mg} / \mathrm{kg}$ : and was 0,14 and 16 . respectively, in Rat B-11 that was treated with the same dose as Rat B-8. All of these rats treated with MA showed no contralateral turns away from the lesioned side.

Associated with the CGU on the $\left[{ }^{14} \mathrm{C}\right] 2$ DG autoradiogram (7) of the above five experimental rats, as for the control rats (Rat W-1 and $W$-2) treated with saline, there was no difference in the CGU between the SNlesioned side and the non-lesioned side. However, for those rats treated with MA at $2.5 \mathrm{mg} / \mathrm{kg}$ (Rat $\mathrm{W}-3$ ) and $5.0 \mathrm{mg} / \mathrm{kg}$ (Rat B5 and $B-11)$, reliable differences between both sides were mainly observed in the $\mathrm{CP}$ and frontal cortex (FC) of the prosencephalon and ventromedial thalamic nucleus (VMT) of diencephalon, as shown in Table 1. Comparing both sides of the aforementioned (see Table 1) brain areas, the relative amount of CGU's in the contralateral side is higher than in the SN lesioned side. As seen in this table, in Rat W-3 that was treated with MA at a dose of $2.5 \mathrm{mg} / \mathrm{kg}$, there were differences in both sides in the FC, CP, LT and VMT. And regarding Rat $\mathrm{B}-5$ and $\mathrm{Rat} B-11$ that were treated with MA at a dose of $5.0 \mathrm{mg} / \mathrm{kg}$, there were evident differences between the FC, $\mathrm{CP}$ and VMT. Figure 1 shows an autoradiogram of Rat W-3 that was treated with MA. This rat was lesioned at the right side of the SN (i.e., the lesioned side is left on the color display). Differences on the CGU between both sides were recognized on areas of the FC (section A level, A: $8.6 \mathrm{~mm}$ ). CP (section A level, A: $8.6 \mathrm{~mm}$ ), LT and VMT (section C level, A: $4.6 \mathrm{~mm}$ ).

Turning behavior in rats with unilateral lesions of the nigrostriatal system has been induced by an imbalance of the nigrostriatal dopamine activity between the two extrapyramidal systems $(1,3)$. In the present study. MA produced marked increases of ipsilateral turning toward the lesioned side as well as

MA at a dose of $2.5 \mathrm{mg} / \mathrm{kg}$, i.p., are shown in the CP and $F C$ of the prosencephalon and the LT and VMT of the diencephalon in rats with electrocoagulation of the unilateral SN. FC: frontal cortex, CP: caudatus putamen, GP: globus pallidus, LT: lateral thalamic nucleus, and VMT: ventromedial thalamic nucleus. 
an imbalance of $\mathrm{CGU}$ predominantly in $\mathrm{CP}$ and $F C$ of the prosencephalon and VMT of the diencephalon, and SC of the mesencephalon among rats with unilateral electrocoagulation of the SN. The imbalance of CGU in the aforementioned areas may be related to the development of ipsilateral turning behavior. It is likely that as MA acts predominatly on these brain areas with intact nigral input, the MA increases the dopamine release from presynaptic nigrostriatal nerve endings. Therefore, the increase of CGU observed in the contralateral brain site toward the lesioned side may be mainly attributed to the activating effect of the postsynaptic nerve as influenced by presynaptic innervation originating from the SN on the intact side. However, we should take into consideration the secondary influence on the $\mathrm{CGU}$ resulting in the development of turning behavior.

It is recognized by studies with the histochemical technique that high concentrations of dopamine in the CP was present in the terminal of a pathway originating in the SN (10). The turnover of dopamine is considered to be regulated by a feedback control pathway from the CP to the SN (11). It is known that the $\mathrm{SN}$ of the rat projects not only to the $\mathrm{CP}$, but also to various thalamic nuclei $(12,13)$. The contralateral increase of CGU produced by MA in this present experiment may be related to the nerve connections of these brain areas.

In conjunction with their study on the thalamus and turning behavior, Kilpatrick et al. (6) suggested that information controlling the locomotion may pass along the CP-SN-thalamus circuit in the turning behavior of the rodent model. There is, also, substantial data that the stimulation of dopamine receptors in the $\mathrm{CP}$ activates the efferent CP-entopedunclar nucleus, CP-SN GABAergic pathways and also the GPsubthalamus GABAergic pathway $(14,15)$. In addition, studies of the outputs from the SN showed that unilateral output is from the SN pars reticulata to the VMT (12-14). In this experiment, the increases of CGU were observed in the CP and VMT, but not in the GP. The probable reason is that facilitation of the VMT is attributed to the CP-SN-VMT circuit (6). Furthermore, Garcia-Munoz et al.
(15) observed that the turning behavior induced by apomorphine in rats lesioned with 6 -hydroxydopamine is inhibited if a lesion is made in the ipsilateral VMT, suggesting the possibility of a functional relationship between the SN and VMT. Therefore, it may be very reasonable to consider that the high CGU in the contralateral VMT toward the $\mathrm{SN}$-lesioned side is attributable to the predominant activating effect of MA on the VMT with intact nigral input. On the other hand, it is well-known that the GP receives neurons from the striatum (14). However, in the present experiment. MA did not cause a marked imbalance of CGU in the GP.

Glick and Greenstein (16) suggested that the $\mathrm{FC}$ modulated a dopaminergic nigrostriatal system. The frontal cortex receives a dopaminergic projection from the midbrain (17). Therefore, the increase of CGU in the contralateral $F C$ induced by $M A$ in rats with unilateral coagulation of the SN might be dependent upon the activation of the FC with intact midbrain dopaminergic input.

Acknowlegment: The authors are indebted to Professor Charles R. Gallistel, University of Pennsylvania, for his valuable advice.

\section{References}

1 Garcia-Munoz, M., Nicolaou, N.M., Tulloch, I.F., Wright, A.K. and Arbuthnott, G.W.: Feedback loop or output pathway in striato-nigral fibres? Nature 265, 363-365 (1977)

2 Crow, T.J.: The relationship between lesion site, dopamine neurons, and turning behavior in the rat. Exp. Neurol. 32, 247-255 (1971)

3 Glowinski, J. and Axelrod, J.: Effect of drugs on the uptake, release, and metabolism of $\mathrm{H3}$ norepinephrine in the rat brain. J. Pharmacol. Exp. Ther. 149, 43-49 (1965)

4 Carlsson, A., Fuxe, K., Hamberger, B. and Lindqvist. M.: Biochemical and histochemical studies on the effects of imipramine-like drugs and $(+)$-amphetamine on central and peripheral catecholamine neurons. Acta Physiol. Scand. 67, 481-497 (1966)

5 Rouzaire-Dubois, B., Hammond, C., Hamon, B. and Feger, J.: Pharmacological blockade of the globus pallidus-induced inhibitory response of subthalamic cells in the rat. Brain Res. 200, 321329 (1980)

6 Kilpatrick, I.C., Starr, M.S., James, T.A. and MacLeod, N.K.: Evidence for the involvement of 
nigrothalamic GABA neurons in circling behaviour in the rat. In GABA and the Basal Ganglia. Edited by Di Chiara, G. and Gessa, G.L., p. 205-224, Raven Press, New York (1981)

7 Sokoloff, L., Reivich, M., Kennedy, C., Des Rosiers, M.H., Patlak, C.S., Pettigrew, K.D., Sakurada, $O$. and Shinohara, $M$ : The $\left[{ }^{14} \mathrm{C}\right]$ deoxyglucase method for measurement of local cerebral glucose utilization: Theory, procedure, and normal values in the conscious and anesthetized albino rat. J. Neurochem. 28, 897-916 (1977)

8 De Groot, J.: The Rat Forebrain in Stereotaxic Coordinates. 4th edn., Elsevier/North-Holland, Amsterdam (1972)

9 Gallistel, C.R., Gomita, Y., Yadin, E. and Campbell, K.A.: Forebrain origins and terminations of the medial forebrain bundle metabolically activated by rewarding stimulation or by reward-blocking doses of pimozide. J. Neurosci. 5, 1246-1261 (1985)

10 Hokfelt, J. and Ungerstedt, U.: Electron and fluorescence microscopical studies on the nucleus caudatus putamen of the rat after unilateral lesions of ascending nigrostriatal dopamine neurons. Acta Physiol. Scand. 76, 415426 (1969)

11 Carlsson, A. and Lindquist, $M$ : Effect of chlorpromazine or haloperidol on formation of 3-methoxytryptamine and normetanephrine in mouse brain. Acta Pharmacol. (Kbh.) 20, 140144 (1963)

12 Clavier, R.M., Atmadja, S. and Fibiger, H.C.: Nigrothalamic projections in the monkey as demonstrated by orthograde and retrograde tracing techniques. Brain Res. Bull. 1, 379-384 (1976)

13 Herkenham, M.: The efferent and afferent connections of the ventromedial thalamic nucleus in the rat. J. Comp. Neurol. 183,487-518 (1979)

14 Scheel-Krüger, J. and Magelund, G.: GABA in the entropeduncular nucleus and the subthalamic nucleus participates in mediating dopaminergic striatal output functions, Life Sci. 29, 1555-1562 (1981)

15 Garcia-Munoz, M., Patino, P., Wright, A.J. and Arbuthnott, G.W.: Anatomical substrate of the turning behaviour seen after lesions in the nigrostriatal dopamine system. Neuroscience 8, 87-95 (1983)

16 Glick, S.D. and Greenstein, S.: Possible modulating of frontal cortex on nigro-striatal function. Br. J. Pharmacol. 49, 316-321 (1973)

17 Berger, B., Thierry, A.M., Tassin, J.P. and Moyhe, M.A.: Dopaminergic innervation of the prefrontal cortex: a fluorescence histochemical study. Brain Res. 186, 133-145 (1976) 